\title{
Ser professor: as experiências humanizadoras proporcionadas pelo Estágio Supervisionado I
}

\author{
Being a teacher: the humanizing experiences provided by the \\ Supervised Internship I
}

\author{
Thaís Gregório Xavier ${ }^{1}$ \\ Bruna Lima de Bairros ${ }^{2}$
}

\begin{abstract}
Resumo
O presente trabalho tem por objetivo principal relatar as experiências vividas durante o cumprimento da Regência do Estágio Supervisionado I, do curso de Letras - Português do Instituto Federal do Espírito Santo - Campus Venda Nova do Imigrante. No estágio, foram acompanhadas turmas de sextos e oitavos anos da Escola Estadual de Ensino Fundamental "Domingos Perim"; todavia, para a Regência, optou-se pelos oitavos anos. A partir disso, Consciência Negra foi o tema escolhido a ser trabalhado. 0 período de Regência durou o total de 5 aulas, divididas entre teoria, pesquisa, produção e apresentação do produto final. Preliminarmente, pode-se perceber a demasiada importância dessa disciplina para a formação de professores, uma vez que tem-se o contato com o meio educacional, fato que auxilia na preparação do futuro profissional da educação e, sobretudo, na união entre a teoria, aprendida em sala de aula, e a prática, aprendida pelo convívio social.
\end{abstract}

Palavras-chave: Relato de Experiência. Docência. Consciência Negra.

\section{Abstract}

The main objective of this work is to report the experiences lived during the fulfillment of the Supervised Internship I Regency, of the course of Letters - Portuguese by the Federal Institute of Espírito Santo - Campus Venda Nova do Imigrante. During the internship, sixth- and eighth-year classes from the State Elementary School "Domingos Perim" were followed, however for the Regency, the eighth years were chosen. From this, the theme chosen to be worked on was Black Consciousness. The Regency period lasted a total of 5 classes, divided between theory, research, production and presentation of the final product. Preliminarily, one can perceive the importance of this discipline for the formation of teachers, since there is a direct contact with the educational environment, a fact that helps in the preparation of the future professional of education and, above all, in the union between theory, learned in the classroom, and practice, learned through social interaction.

Keywords: Experience report. Teaching. Black Consciousness.

\section{Introdução}

A Escola Estadual de Ensino Fundamental Domingos Perim situa-se em um bairro próximo ao centro da cidade e atende, no período matutino, o total de 324 alunos matriculados e 22 professores regentes ${ }^{3}$. A instituição é composta por 12 salas de aula, 01 biblioteca, 01 sala de informática - são 13 computadores no total, mas, infelizmente, nem todos funcionam - 01 sala de vídeo, 01 quadra e 01 pátio externo. Além dessas dependências, há as salas de professores, da pedagoga, de planejamento, de

\footnotetext{
${ }^{1}$ Graduanda em Licenciatura em Letras com Habilitação em Português. Instituto Federal do Espírito Santo - Campus Venda Nova do Imigrante. Orcid: https://orcid.org/0000-0003-3492-8205/ E-mail: thaisgregor@hotmail.com

2 Graduanda em Licenciatura em Letras com Habilitação em Português. Instituto Federal do Espírito Santo - Campus Venda Nova do Imigrante. Orcid: https://orcid.org/0000-0001-7913-3049/ E-mail: bruna.bairros02@hotmail.com

3 Tais informaç̃̃es se baseiam nos meses de Agosto a Novembro de 2019.
} 
coordenação, de AEE (Atendimento Educacional Especializado) e a secretaria. Há banheiros femininos e masculinos nos dois andares da escola.

As turmas, em sua maioria, possuem de 30 a 35 alunos e são formadas por alunos entre $14 \mathrm{e}$ 18 anos. Nesse sentido, as turmas em foco para este relato de experiência se constituem pelos oitavos anos. Preliminarmente, ressalta-se a carência dos alunos em se tratando de novas práticas pedagógicas que visem a sua participação iminente.

A partir das atividades e do convívio, nós, professoras, deixamos de ser o "bicho estranho" na sala e passamos a ser uma espécie de refúgio. A nós são reservados desabafos, lamentos e até reclamações quanto a atual forma com que eles, teoricamente, "aprendem". Participamos não só do cotidiano dos alunos, mas alguma parte da vida deles fora da escola nos é reservada. Nos foram confiados diversos segredos, os quais nunca mais serão ditos novamente e talvez sejam esquecidos daqui umas horas; boa parte se resolverá, a outra parte que punge os perseguirá pelo resto de suas vidas. É triste que não podemos simplesmente dar uma receita para que os problemas sejam resolvidos de imediato. Não temos a receita da vida, o que temos são as possibilidades de aprendizado, o ensinar a evoluir, a mudar, a se metamorfosear, posto que preferimos ser essa metamorfose ambulante do que termos aquela velha opinião formada sobre tudo4.

A prática junto da reflexão é demasiadamente importante. Dessa maneira, para uma interpretação da realidade a partir das experiências, o conceito de materialismo histórico-dialético -, preconizado por Marx - nos é bem-vindo aqui. Este método busca investigar as leis e fenômenos sociais e captar cada detalhe dos processos evolutivos. Segundo Pires:

[...] caracteriza-se pelo movimento do pensamento através da materialidade histórica da vida dos homens em sociedade, isto é, trata-se de descobrir (pelo movimento do pensamento) as leis fundamentais que definem a forma organizativa dos homens durante a história da humanidade. (PIRES, 1997, p. 87).

É a partir da observação da realidade que se tem o processo de desenvolvimento do sujeito. Por meio de uma concepção dialética da educação, é possível contribuir para a formação pessoal. Dessa maneira, o método materialista ajuda no entendimento epistemológico sobre as práticas e processos educativos. A teoria, bem como a prática, é mesclada e resulta na integração das ações, o que contribui para a formação ampla.

4 Referência à música "Metamorfose Ambulante" de Raul Seixas, lançada em 1973 e disponível em: https://www.youtube.com/watch?v=7VE6PNwmr9g 
Formal ou informal, institucionalizada ou não, a Educação assume diversas possibilidades e modalidades. Além de ser um princípio de emancipação, contribui para o reconhecimento de si e do mundo. Nas palavras de Pimenta e Lima (2012, p. 126): "[...] o estágio passa a ser um retrato vivo da prática docente e o professor-aluno terá muito a dizer, a ensinar, a expressar sua realidade e a de seus colegas de profissão, de seus alunos, que nesse mesmo tempo histórico vivenciam os mesmos desafios e as mesmas crises na escola e na sociedade".

Nesse sentido, este relato de experiência destina-se aos professores e professoras de Língua Portuguesa que têm por intenção utilizar as temáticas de "Consciência Negra e Racismo" em suas aulas como recurso para o desenvolvimento social e cultural dos educandos. A pertinência de tal relato se pauta, então, na necessidade de se problematizar e refletir acerca da sociedade atual e as diversas formas de preconceito existentes e perpetuadas todos os dias. Articulado às teorias de Munanga e Gomes (2006), além de nos pautar nas leis 11.645/2008 e 10.639/2003, relataremos as experiências de ensino vivenciadas por meio da disciplina Estágio Supervisionado I - Anos Finais do Ensino Fundamental. Acredita-se que é de extrema urgência trazer para o cotidiano dos alunos a criticidade, bem como a promoção de reflexão perante a sociedade vigente, fato reiterado ao longo desse relato.

\section{Fundamentação teórica}

A título de embasar os conhecimentos aqui propostos, utilizamos os conceitos de Munanga e Gomes (2006) acerca da diferença entre racismo, discriminação e preconceito. Além disso, como já é de praxe, utilizamos a Lei 11.645/2008 - a qual versa sobre a inclusão no currículo da rede de ensino a temática da História e cultura afro-brasileira e indígena - e a Lei 10.639/2003 - a qual determina o dia 20 de novembro como o dia da Consciência Negra.

Para Munanga e Gomes (2006), o termo raça é, de certa forma, contraditório, uma vez que pode ser usado em diferentes possibilidades de comunicação e, dependendo da forma como é usado, pode evidenciar um complexo campo de relações, as quais são estabelecidas entre os povos negros e os brancos.

Tal conceito pode abarcar uma significação no campo das ciências naturais, pois define as classes dos animais que possuem uma origem comum com aspectos e potencialidades físicas específicas ao seu parentesco. A partir dessa perspectiva, durante a II Grande Guerra, o nazismo e seus adeptos denotaram um sentido biológico ao vocábulo, a fim de justificar a ideia de que a raça branca e ariana seria superior aos outros grupos, o que culminou na segregação e na morte de milhares de pessoas (MUNANGA E GOMES, 2006).

LínguaTec, Instituto Federal de Educação, Ciência e Tecnologia do Rio Grande do Sul, Bento Gonçalves 
Todavia, o Movimento Negro faz, atualmente, uso dessa sentença como forma de evidenciar suas características, isto é, rejeita-se tal conceito de supremacia e relaciona-se ao fato de reconhecer a diferença entre os grupos sociais, sem a atribuição de qualidades positivas ou negativas. Nesse sentido, por meio da apropriação do termo, o Movimento Negro tenta denunciar o racismo, uma vez que alerta acerca das desigualdades sociais enfrentadas pela população negra no Brasil. Portanto, dependendo da situação e da forma como se diz, a palavra pode ser negativa e conter ideias racistas, porém também pode servir para o autoconhecimento e compreensão da própria história (MUNANGA E GOMES, 2006).

As diferenças, portanto, são construções sociais, políticas, culturais e econômicas. Tudo isso reafirma e perpetua os valores aos quais estamos submetidos quando se trata das relações de poder. Dessa maneira, a diversidade está em todos os âmbitos sociais, logo que a questão racial está inserida neste grande tema.

O termo "etnia", nesse sentido, é considerado mais adequado, pois seu sentido não abarca a questão biológica que é atribuída à raça. Tal uso se firmou pois abrange a diversidade dos povos, sejam estes judeus, índios, negros, etc. Essa nomenclatura visa ratificar o pertencimento ancestral e étnicoracial do povo negro (MUNANGA E GOMES, 2006).

Todavia, a questão maior não é a de delimitação das expressões que devem ser usadas. Ambas - raça e etnia - devem, pois, serem consideradas de forma igual, logo que essa complexidade de definição é o que representa e legitima a identidade do negro brasileiro.

O racismo, nesse sentido, de acordo com Munanga e Gomes (2006), é fruto da aversão bem como do ódio àquelas pessoas que não pertencem, racialmente falando, ao padrão estabelecido. Tal padrão se constitui por sinais como a cor da pele, o tipo do cabelo, o formato do olho, do nariz, etc. Deste modo, as atitudes racistas resultam da crença de uma supremacia racial, na qual há a imposição de apenas uma das raças como a perfeita. Esses aspectos foram evidenciados pelas teorias raciais, no século XIX, por exemplo, o que levou à exclusão, à discriminação racial e ao extermínio em massa.

Assim sendo, tem-se a expressão de duas formas de racismo, que estão interligadas: a individual e a institucional. A primeira é manifestada por atos discriminatórios de um indivíduo contra outros. Níveis extremos podem ser atingidos, tais como a violência, agressões, destruição de bens e propriedades e, muitas vezes, assassinatos.

Já a forma institucional pressupõe práticas discriminatórias sistemáticas, as quais podem ser fomentadas pelo Estado. Sua manifestação se dá por meio de isolamento da população negra em alguns bairros, - as periferias são um exemplo disso - em escolas e em empregos, assim como o genocídio, a limpeza étnica e a tortura. 
Há a recorrente confusão entre os conceitos de "racismo" e "etnocentrismo"; todavia, para Munanga e Gomes (2006), o segundo aponta para o sentimento de superioridade que uma determinada cultura pode exercer sobre as outras. Acredita-se, portanto, que os valores, os princípios, as convicções e a moral devem ser considerados absolutos e fundamentais, o que generaliza as concepções culturais de cada povo.

O etnocentrismo está, de fato, imbricado na sociedade e, por causa disso, torna-se laborioso controlar e até mesmo erradicar tal problema. Este conceito é o caminho para o racismo - visto aqui como 0 ato, a ação. $O$ etnocentrismo é o pensamento, a ideia. Já o racismo é a aplicação dessas ideias em atitudes discriminatórias -, pois a partir do momento em que há a perpetuação da prática racista, esta já se constitui e se classifica como racismo.

O preconceito é efeito de um pré-julgamento que os membros de um grupo social têm em relação a uma raça, uma etnia, uma religião. Tal julgamento prevê como aspecto principal a inflexibilidade de ideias. Há uma tendência à manutenção de um ideal, mesmo que haja fatos e dados contestadores dessas proposições.

A incidência do preconceito racial no Brasil ratifica a existência de todo um sistema racista (social, político, cultural e econômico) que, cada vez mais, perpetua e produz as desigualdades raciais presentes dentro da sociedade brasileira. O preconceito racial é, portanto, fruto do racismo, o qual acredita numa supremacia racial, sendo esta fonte principal e provedora do preconceito em relação às raças.

Dessa maneira, há, visualmente, a semelhança entre a discriminação e o preconceito, uma vez que ambos têm por ideia central a promoção de atitudes e sentimentos negativos de um grupo em relação a outro. Todavia, define-se o verbo "discriminar" como o ato de distinguir, diferenciar e discernir. Nesse sentido, a discriminação racial se constitui da prática do racismo, bem como a efetivação do preconceito racial (MUNANGA E GOMES, 2006).

Vale ressaltar que a diferença entre esses dois aspectos se dá da seguinte forma: a discriminação racial é a ação de uma pessoa contra outra pessoa, enquanto o preconceito se constitui à base das ideias. Em outras palavras, o preconceito é o que leva à discriminação, e essa, portanto, é o ato em si, motivada pelo preconceito.

\section{Descrição da experiência}

Quando adentramos nessa experiência, nós, discentes do $6^{\circ}$ período do curso de Licenciatura em Letras/Português do Instituto Federal do Espírito Santo, na cidade de Venda Nova do Imigrante, não imaginávamos que pequenas coisas no âmbito escolar iriam enriquecer tanto nosso ser docente. Antes 
de iniciar a regência, conversamos com a professora tutora a fim de saber qual tema ela nos indicaria para abordar nas turmas de oitavos anos. Feito isso, tivemos em mãos uma lista com variados temas e um nos chamou atenção, sendo ele a Consciência Negra. Estávamos com receio de fazer a regência nas duas turmas de oitavo ano ( $8^{\circ} \mathrm{M} 01$ e $8^{\circ} \mathrm{M} 02$ ), posto que são consideradas as turmas mais falantes e bagunceiras da escola; mas, para a nossa surpresa, ao longo das aulas as duas turmas abraçaram a ideia e o resultado foi alcançado com base no nosso objetivo preliminar.

Para uma melhor distribuição do conteúdo, fizemos um planejamento que gerou, no seu produto final, 5 aulas. Na primeira aula, introduzimos 0 assunto da aula fazendo diálogo com a música "Canção Infantil - Cesar Mc part. Cristal", sobre preconceito e racismo. Para esta primeira etapa, pensamos em uma aula interativa. Dessa forma, fizemos quatro perguntas e, ao longo de cada questionamento, pedíamos que os alunos comentassem o que sabiam e, se não sabiam, o que pensavam sobre 0 assunto. As perguntas eram: $\mathrm{O}$ que é preconceito? $\mathrm{O}$ que é racismo? $\mathrm{O}$ que é consciência negra? Por que comemoramos essa data?

Nesta aula, os alunos ainda estavam um pouco acanhados em participar e expor suas opiniões. Contudo, aos poucos, os discentes ficaram mais confortáveis com o ambiente proporcionado por nós. Dessa forma, sua contribuição para a aula foi iminente. Para nossa surpresa, muitos não sabiam diferenciar bullying de racismo, ou preconceito de discriminação. Alguns não sabiam o que era preconceito e, com base nas indagações dos estudantes, mediamos a conversa e, aos poucos, fomos esclarecendo as dúvidas. Colocamos no quadro as palavras-chave que eles falavam, como: pré-conceito, bullying, preconceito, discriminação, racismo, raça, cultura, cor, entre outras. Depois disso, distribuímos uma folha com a letra da música Canção Infantil para cada um e, após ouvi-la, debatemos sobre os temas que a música tratava, com base na conversa que tivemos.

$\mathrm{Na}$ segunda aula, dialogando com o que foi feito na primeira, levamos os alunos para a sala de vídeo e mostramos alguns exemplos de poesia cantada. Alguns vídeos mostrados foram tirados de competições de rua (slam), além de debater um pouco sobre a percepção dos discentes acerca dos temas racismo e preconceito. Aqui, a proposta era que os alunos trouxessem o assunto para mais perto da realidade. Após a exibição dos exemplos, tiramos dúvidas e falamos sobre os temas que os vídeos tratavam, lembrando sempre sobre racismo, consciência negra, preconceito, etc.

Nesse dia, foram sugeridas à discussão mais palavras-chave, como: colorismo, embranquecimento da sociedade, período da escravidão, cabelo afro, religião, e vários outros. É importante destacar a vontade dos alunos de falar sobre o tema, a vontade de participar e os comentários produtivos sobre a vida pessoal de cada um, além dos meios de combate que os próprios estudantes estimularam ao longo da conversa. 
Após isso, foi explicado como seria a atividade produzida por eles. Os discentes deveriam escrever poemas, parecidos com os slams, e apresentá-los para toda a turma. Deixamos os estudantes livres para decidirem se gostariam de fazer a atividade sozinhos ou em grupo. Eles se organizaram da forma como preferiram e, após o tempo de discussão, eles nos entregaram uma relação dos componentes dos grupos.

Na terceira aula convidamos Filipe Souza, um poeta do Estado que participa de competições de poemas pelo país, para explicar como é a sua produção criativa para escrever as poesias, além de dar dicas para a produção dos alunos. Os estudantes ficaram muito empolgados com a participação de Filipe, tanto que fizeram várias perguntas e pareceram bem curiosos para saber cada vez mais sobre o poeta.

Sua apresentação foi pensada para que os alunos se sentissem mais à vontade para escrever com base em tudo que foi refletido até aquele momento, além de ser um momento diferenciado nas aulas, uma novidade para os alunos. Filipe, em sua apresentação, contou um pouco da sua história escrevendo poemas, declamou dois poemas nas turmas e tentou interagir com os alunos, que ficaram curiosos e atentos sobre cada fala do poeta. A aula foi produtiva pois, a partir dela, as turmas entenderam como fazer um poema, se sentindo inspiradas para a escrita.

Na penúltima aula, sendo o quarto dia e o dia de produção, os alunos sentaram em grupos e começaram a rascunhar poemas sobre o tema que foi tratado até então e, com nosso auxílio, surgiram poemas que nos causaram reflexão e, ao mesmo tempo, uma satisfação imensa por observar 0 engajamento de criação que cada aluno apresentou. Quando estávamos indo de mesa em mesa para ajudar os grupos, percebemos que a maioria das dúvidas que eles tiveram ao longo das aulas foi sanada, uma vez que, ao longo dos versos dos poemas, eles explicaram algumas das palavras-chave utilizadas nas aulas.

$\mathrm{Na}$ última aula os alunos estavam empolgados e ansiosos para mostrar suas produções. Em vista disso, organizamos a sala em roda e os grupos que se sentissem confortáveis para apresentar se dirigiam para frente da sala e declamavam seus poemas. Nos emocionamos com as poesias, pois elas tinham um teor reflexivo e todos demonstraram entendimento do que foi ensinado até então. Recebemos cada texto separado em uma folha para avaliarmos tanto a escrita quanto a adequação ao tema.

O objetivo principal desta sequência de atividades era promover a reflexão acerca do racismo na sociedade brasileira, bem como a importância da Consciência Negra, a identificação e o reconhecimento das formas de preconceito na sociedade, a criação de hipóteses para o combate do racismo no cotidiano a partir dos exemplos usados em sala de aula, e, essencialmente, desenvolver a criticidade em relação aos padrões sociais vigentes. Ao concluir a atividade, foi possível perceber que os objetivos foram alcançados.

LínguaTec, Instituto Federal de Educação, Ciência e Tecnologia do Rio Grande do Sul, Bento Gonçalves v. 5, n. 1, p. 227-237, nov. 2020. 
Concluindo, o período de regência no estágio foi um caminho árduo, difícil e diversas foram as barreiras a serem enfrentadas. Trabalhamos com duas turmas que achávamos que seria impossível trabalhar pela intensa conversa e desrespeito. Porém, nos surpreendemos com o feedback que ambas as turmas nos deram. Houve participação, cooperação e, no final, todos produziram excelentes textos. Com isso, percebemos que é possível criar vínculo entre os alunos e as diversas disciplinas. A satisfação que tivemos em relação a nossa dedicação mostrou que vale a pena trilhar esse caminho na docência.

\section{Avaliação dos resultados}

Saviani (2007) afirma que a Educação é a produção e a mediação do saber e, por esse fato, ela possui uma diversidade quando se fala em sua conceituação, isto é, a educação é uma forma de intervir no mundo. Esta se constitui da observação, da imitação, do entendimento e da aprendizagem.

Nesse sentido, de acordo com Pimenta e Lima:

O professor no espaço do estágio tem a possibilidade de se reconhecer como sujeito que não apenas reproduz o conhecimento, mas também pode tornar seu próprio trabalho de sala de aula em um espaço de práxis docente e de transformação humana. É na ação refletida e no redimensionamento de sua prática que o professor pode ser agente de mudanças na escola e na sociedade. (PIMENTA E LIMA, 2012, p. 132, grifos nossos).

Pautando-se nessa perspectiva da formação de agentes de mudança social, percebemos a demasiada necessidade dos alunos terem contato com o novo, posto que, cansados das aulas cotidianas, nas quais se usa de forma enfadonha o livro didático e se exclui a proposição de atividades diversificadas e lúdicas, os discentes têm sua singularidade e originalidade deslegitimadas, o que contribui para a mecanização dos saberes.

É possível visualizar que há uma juntura entre a produção e a formação do homem, o que gera um processo educativo. A educação é permeada de uma relação de identidade, o que coincide com a origem plena do homem. Baseia-se na ideia do aprender fazendo, pois "[...] os homens aprendiam a produzir sua existência no próprio ato de produzi-la." (SAVIANI, 2007, p. 154)

É a partir da observação da realidade que se tem o processo de desenvolvimento do sujeito. Por meio de uma concepção dialética da educação é possível contribuir para a formação pessoal. Dessa maneira, o método materialista ajuda no entendimento epistemológico sobre as práticas e processos educativos. A teoria, bem como a prática, é mesclada e resulta na integração das ações, o que contribui para a formação ampla do sujeito (LEITE, 2019). 
Outro fato observado foi a assimilação dos conteúdos e das ideias propostos por nós durante as aulas. Os estudantes, por meio de suas produções, mostraram compreender o que foi exposto, posto que, de maneira crítica e reflexiva, expressaram alguns aspectos, como a diferença entre bullying e racismo, bem como as dificuldades enfrentadas pelo sujeito negro na sociedade.

Desde o começo, o medo nos deixou receosas. Contudo, tal sentimento nunca foi motivo de estagnação. Nunca nos paralisamos frente às adversidades, muito pelo contrário: 0 medo foi 0 combustível gerador de nossas motivações, e os resultados obtidos - principalmente o retorno dos alunos e da professora tutora - foram demasiadamente satisfatórios. Citando um de nossos alunos: "nunca é um adeus. Sempre é um até logo". Dizemos "até logo" para aqueles que cruzaram nosso caminho até aqui trilhado, pois um novo começo nos chama e nós, como seres inacabados que somos, aguardamos nosso novo destino.

\section{Considerações finais}

Nas palavras de Pimenta e Lima (2012, p. 131): "O homem precisa reaprender a pensar". Entretanto, "o simples exercício de reflexão não é garantia de salvação dos cursos de formação de professores, pois a reflexão não é um processo mecânico". É por esse motivo, então, que sua compreensão se dá por meio de uma perspectiva histórica e coletiva, uma vez que é realizada a partir da autoanálise acerca das práticas adotadas em sala de aula.

O estágio, nesse sentido, é uma experiência enriquecedora, principalmente no que tange à (re)formulação das práticas e dos métodos dos futuros professores. Percebe-se a iminente necessidade de tal disciplina para a constituição de um profissional qualificado para as diversas situações cotidianas.

A escola é lugar do novo, do amplo, do diverso, da reflexão, da promoção dos direitos, da consciência de mundo, da autonomia. Nesse sentido, é imprescindível que neste ambiente seja adotada uma visão que contemple os alunos e alunas, possibilitando a compreensão das implicações sociais, éticas, econômicas, políticas e ideológicas. A escola não deve funcionar como uma transmissora de ideias liberalistas, muito menos conservadoras e tradicionais. Ela deve promover o debate e jamais deve privar o aluno de pensar por si mesmo. A título de considerações, fazemos nossas as palavras de Rubem Alves:

Há escolas que são gaiolas. Há escolas que são asas. Escolas-gaiolas existem para que os pássaros desaprendam a arte do vôo. Pássaros engaiolados são pássaros sob controle. Seu dono pode levá-los aonde quiser. Deixaram de ser pássaros, pois a essência dos pássaros é 0 vôo. Escolas-asas não amam pássaros engaiolados. Amam os pássaros em vôo. Ensinar 0 
vôo não podem, porque o vôo já nasce dentro dos pássaros. 0 vôo só pode ser encorajado. (ALVES, 2011).

A Educação forma cidadãos e estes cidadãos têm a possibilidade de tomar os meios de produção e fazer a mudança. Contudo, considerando o atual contexto político, econômico e ideológico do Brasil, de que forma ou de quais formas os educadores podem instigar os educandos à empatia e ao reconhecimento de si? Como fazer isso, se a todo momento os assuntos transversais são rechaçados e quem se atreve a trabalhar com eles é vítima dos dizeres apartidários e neutralizadores?

Já sabemos e estamos cansados de ouvir que a neutralidade não existe e que é impossível ser apartidário num ambiente ideológico e político como a escola, mas como explicar isso a quem não está apto a escutar? Como se fazer entender para pessoas que já estão imersas em seu próprio mundo, em seus próprios ideais?

Em outras palavras, o professor é a figura principal, tanto no encorajamento quanto no encarceramento dos alunos. Escolher qual tipo de professor ser reflete não só nos discentes, mas também em si mesmo. Cabe a nós, futuros educadores, encorajar o voo dos nossos pássaros para mostrar-lhes as possiblidades e os caminhos. A escolha de cada um será individual, mas o incentivo é coletivo.

\section{Referências}

ALVES, R. Gaiolas ou asas?: O vôo, signo da liberdade, só pode ser encorajado. 2011. Disponível em: https://www.revistaeducacao.com.br/gaiolas-ou-asas/. Acesso em: 29 nov. 2019.

BRASIL. Lei 11.645. Brasilia, DF, Disponível em: http://www.planalto.gov.br/ccivil_03/_Ato20072010/2008/Lei/L11645.htm. Acesso em: 11 nov. 2019.

BRASIL. Lei 10.639. Brasília, 09 jan. 2003. Disponível em: http://www.planalto.gov.br/ccivil_03/leis/2003/L10.639.htm. Acesso em: 11 nov. 2019.

CESAR MC - Canção Infantil part. Cristal. Vitória: Pineapple Storm Records, 2019. P\&B. Disponível em: https://www.youtube.com/watch?v=Ri-eF5PJ2X0. Acesso em: 11 nov. 2019.

LEITE, Priscila de Souza Chisté. Contribuições do materialismo histórico-dialético para as pesquisas em MestradosProfissionaisna área de ensino de humanidades. Investigação Qualitativa em Educação, Vitória, v. $\quad 1, \quad$ p.847-856, 2017. Disponível em: < https://proceedings.ciaiq.org/index.php/ciaiq2017/article/view/1405/1362 >. Acesso em: 10 out. 2020.

MUNANGA, K.; GOMES, N. L. O Negro no Brasil de Hoje. São Paulo: Global, 2006.

PIMENTA, S. G.; LIMA, M. S. L. Estágio e Docência. São Paulo: Cortez, 2012. 
PIRES, Marília Freitas de Campos. O materialismo histórico-dialético e a Educação. Interface, Botucatu, n. 1, p.83-94, ago. 1997. Disponível em:<http://www.scielo.br/pdf/icse/v1n1/06.pdf>. Acesso em: 04 jun. 2019.

SAVIANI, Dermeval. Trabalho e educação: fundamentos ontológicos e históricos. Revista Brasileira de Educação, Campinas, v. 12, n. 34, p.152-180, 2007. Disponível em: <http://www.scielo.br/pdf/rbedu/v12n34/a12v1234.pdf>. Acesso em: 10 out. 2020.

Data de submissão: 24/07/2020. Data de aprovação: 22/10/2020. 